OPEN ACCESS

Edited by:

Mohammed S. Ismail,

The University of Sheffield,

United Kingdom

Reviewed by:

Masli Irwan Rosli,

National University of Malaysia,

Malaysia

Mohamad Y. Mustafa,

UiT The Arctic University of Norway,

Norway

Masamichi Nishihara

Kyushu University, Japan

*Correspondence:

Mohamed R. Berber

mrberber@science.tanta.edu.eg

tORCID:

Mohamed R. Berber

orcid.org/0000-0002-4468-0998

₹Scopus ID:

24831523300

Specialty section:

This article was submitted to

Fuel Cells,

a section of the journal

Frontiers in Energy Research

Received: 11 June 2020

Accepted: 14 August 2020

Published: 10 September 2020

Citation:

Berber MR (2020) Molecular Weight Impact

of Poly(2,5-Benzimidazole) Polymer on Film Conductivity, Ion Exchange Capacity, Acid Retention Capability,

and Oxidative Stability.

Front. Energy Res. 8:571651. doi: 10.3389/fenrg.2020.571651

\section{Molecular Weight Impact of Poly(2,5-Benzimidazole) Polymer on Film Conductivity, Ion Exchange Capacity, Acid Retention Capability, and Oxidative Stability}

\author{
Mohamed R. Berber ${ }^{1,2 * t \neq}$ \\ ${ }^{1}$ Chemistry Department, College of Science, Jouf University, Sakaka, Saudi Arabia, ${ }^{2}$ Department of Chemistry, Faculty \\ of Science, Tanta University, Tanta, Egypt
}

In order to show the impact of the molecular weight (MW) of poly(2,5-benzimidazole) (ABPBI) on its physicochemical properties, a series of $\mathrm{ABPBI}$ polymers with different MWs ranging from 20 to $113 \mathrm{kDa}$ were synthesized and fabricated into conductive films. The ABPBI films are characterized by different spectroscopic methods measuring the acid loading level, acid retention capability, ion exchange capacity (IEC), and the proton conductivity. Notably, the phosphoric acid (PA) loading ratio increased with the increase of $\mathrm{ABPBI} \mathrm{MW}$. The acid retention capability increased by $11 \%$ when the $\mathrm{ABPBI} \mathrm{MW}$ reached $113 \mathrm{kDa}$. The fabricated $\mathrm{ABPBI}$ films exhibited good oxidative stability. A weight loss of only 9 wt\% was observed for the high-MW ABPBI film compared to 19 wt\% for the low-MW ABPBI film after 7 days in Fenton's reagent at $65^{\circ} \mathrm{C}$. The IEC increased with an order of magnitude when the ABPBI MW changed from 20 to $113 \mathrm{kDa}$. A maximum proton conductivity of $8.0 \mathrm{mS} / \mathrm{cm}$ was recorded for the high-MW film at $140^{\circ} \mathrm{C}$, which was $45 \%$ higher than that for the low-MW ABPBI film. The proton conduction process followed the Grotthuss mechanism with a low activation energy ( $9.3 \mathrm{~kJ}$ mol) at the highMW ABPBI film. These results indicated how important the ABPBI MW is in obtaining conductive films with remarkable properties for fuel cell (FC) applications. Prospectively, the findings of the current study can be implemented for other conductive polymers.

Keywords: poly(2,5-benzimidazole), molecular weight, conducting films, physicochemical properties, proton conductivity

\section{INTRODUCTION}

Polymer applications in fuel cell (FC) technology are currently receiving a lot of research interest to improve FC conductivity, oxidative stability, utilization efficiency, durability, and lifetime cycle (Fujigaya et al., 2016; Hafez et al., 2017; Kimura et al., 2020). Many functional polymers have been introduced as proton conductors in FCs, including Nafion, sulfonated poly(ether ether ketone) (sPEEK), polyvinyl sulfonic acid, and polypyrrole polymers (Das and Prusty, 2012; Zhan et al., 2017). These polymers showed different conductivity and stability behaviors at different conditions. Although these polymers have shown remarkable physicochemical properties, the optimum FC 


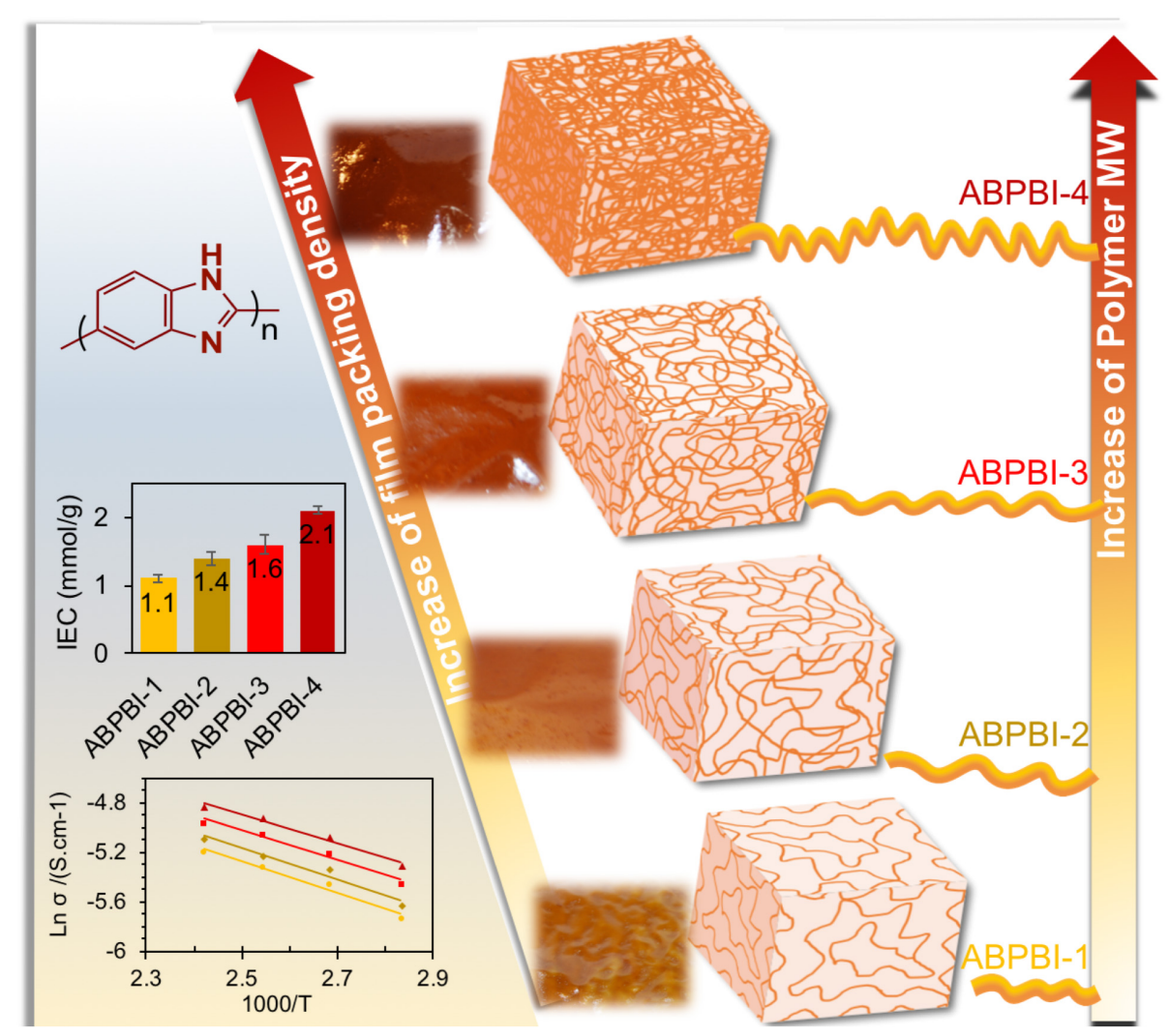

GRAPHICAL ABSTRACT | Molecular weight control of ABPBI polymer to improve PEM conductivity.

performance has not been reached yet (Berber et al., 2018; Nezakati et al., 2018). Thus, there is still a need for materials with high thermal and chemical stabilities as well as high proton conductivities at a wide range of operating conditions of FCs.

Conductive benzimidazole-based polymers have provided remarkable properties for FCs, especially at harsh operating conditions, because they exhibit high-dimensional, chemical, and thermal stabilities; high proton conductivities at high temperatures and anhydrous environments; and good mechanical properties with sufficient thin-film processability (Asensio et al., 2010; Yang et al., 2015). A lot of research efforts were done to improve the conductivity of benzimidazole-based polymers, via copolymerization, grafting, blending, and organicinorganic composite formations (Patra et al., 2016). Although these modification techniques have supported high proton conductivities, most of them have sacrificed the mechanical properties and the film cast processability (Gao et al., 2020a; Kumar et al., 2020). Accordingly, more research studies are still required to counterbalance these shortcomings.

Polymer molecular weight (MW) and nitrogen content in the polymer backbone have played important roles in improving both the proton conductivity and the physicochemical properties (Asensio et al., 2010). Very recently, we synthesized a series of benzene-based benzimidazole polymers with controlled MWs (Berber and Nakashima, 2019b). The cast films of these polymers showed remarkable mechanical properties and proton conductivities at high operating temperatures and anhydrous conditions, thanks to the high MW of the synthesized polymers. Also, we offered high-MW and nitrogen-rich films of a bipyridine-based benzimidazole polymer (Berber and Nakashima, 2019a). These properties provided mechanically and chemically stable films with potential proton conductivities at a wide range of operating temperatures. Thus, we believe that our synthetic technique can be extended to include other benzimidazole-based polymers.

Poly(2,5-benzimidazole) (ABPBI) is one of the most promising conductive polymers in high-temperature FCs because it can be prepared from inexpensive and commercially available single monomers and also possesses high thermal and mechanical stabilities (Nayak et al., 2018). ABPBI accommodates only one imidazole unit per each benzene ring. Thus, it is the simplest and most pronounced member of the polybenzimidazolebased family. Several reports have been offered to improve the proton conductivity of ABPBI (Bao et al., 2015; Liu et al., 2018; Rath et al., 2020). Despite all these trials, the optimum FC performance, in particular the proton conductivity of $\mathrm{ABPBI}$, has not been reached yet.

In the current study, strong attention was paid to the MW control of ABPBI to show its impact on the physicochemical properties of cast ABPBI films for high-temperature FCs. Specifically, ABPBI is synthesized with different MWs to study the influence of polymer MW on acid loading level, 


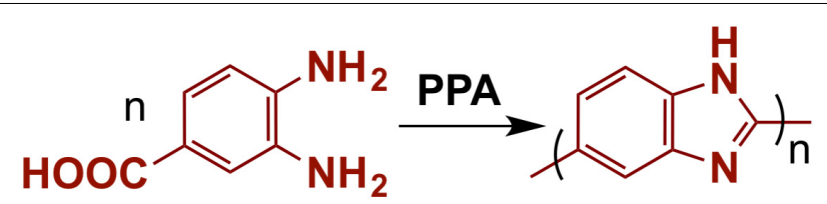

FIGURE 1 | Preparation of ABPBI polymer.

dopant retention capability, oxidative stability, ion exchange capacity (IEC), and proton conductivity. Different spectroscopic techniques are used to characterize the prepared materials, including nuclear magnetic resonance (NMR), Fourier transform infrared (FTIR), and thermal gravimetric analysis (TGA). Subsequently, the proton conduction mechanism is studied to highlight the impact of ABPBI MW on the conduction process.

\section{MATERIALS AND METHODS}

\section{Materials}

3,4-Diaminobenzoic acid (DAB, 97\% grade), trifluoroacetic acid (TFA, 99\% grade), polyphosphoric acid (PPA, 115\%, grade), phosphoric acid (PA, 85\%), and dimethyl acetamide were purchased from Sigma-Aldrich. The common solvents used in the study were purchased from El-Gomhouria for Trading Chemicals and Medical Appliances. DAB was crystallized from hot water before use. All the other chemicals were used as received.

\section{Methods}

\section{Preparation of ABPBI Polymers}

Poly(2,5-benzimidazole) polymers were prepared by a polymerization polycondensation process of $\mathrm{DAB}$ in PPA as a solvent and a dehydrating agent under a $\mathrm{N}_{2}$ atmosphere. The preparation conditions were varied in order to obtain polymers with different inherent viscosities. The synthesized ABPBI polymers were precipitated in hot water, severely washed by 0.2 $\mathrm{M} \mathrm{NaOH}$ to remove any PPA, and finally purified by methanol as the solvent (Hu et al., 1993). The obtained polymers are named ABPBI-1, ABPBI-2, ABPBI-3, ABPBI-4, and ABPBI-5 based on the preparation conditions.

\section{Polymer Dissolution and MW Determination}

All the synthesized polymers were easily dissolved in concentrated sulfuric acid except for ABPBI-5. Different solvents, e.g., methyl sulfonic acid, dimethyl sulfoxide, $\mathrm{N}, \mathrm{N}$ dimethyl formamide, and $\mathrm{N}$-methyl-2-pyrrolidone, have also been applied to test the solubility of ABPBI-5; however, no positive result was obtained. The MWs of the other ABPBI polymers were estimated by the measurement of the inherent viscosity ( $\eta \mathrm{i})$ in concentrated sulfuric acid $(98 \mathrm{wt} \%)$ at $30^{\circ} \mathrm{C}$.

\section{Film Cast of ABPBI Polymers}

Poly(2,5-benzimidazole) polymers were first prepared as highly viscous solutions ( $3 \mathrm{wt} \%$ ) in TFA. TFA was used as the solvent because it can easily be extracted from the cast medium by a mild heating process (Nayak et al., 2018). Next, on a glass plate, the polymer solution was cast. The cast solution was left to stand at room temperature till a sticky film was obtained. The cast medium was gradually heated up to $70^{\circ} \mathrm{C}$ to evaporate the TFA solvent. The formed film was left at this temperature overnight to ensure the removal of all the solvent residue (Asensio et al., 2010). Subsequently, the films were peeled off the glass plate, rinsed several times with methanol, and finally oven-dried.

\section{PA Doping and Retention Processes of ABPBI Films}

The obtained ABPBI films were cut in strips of $3 \times 2 \mathrm{~cm}$ and were put in an $85 \mathrm{wt} \%$ PA solution at room temperature for 5 days to reach the PA adsorption equilibrium (Fujigaya et al., 2014). The films were then removed from the doping medium, wiped several times by a non-woven paper to detach the physically adsorbed PA, and then reweighted to estimate the loaded PA (Yang and He, 2010). The PA doping level was obtained from the weight difference of the undoped and the doped ABPBI films and defined as the moles of PA per the monomeric unit of the ABPBI polymer.

The retention capability of the doped ABPBI films was evaluated by the immersion of the films in boiling water for a period of $6 \mathrm{~h}$. The ratio of the leached PA was determined every $1 \mathrm{~h}$, by removing the ABPBI films and recording its dry weight. The PA loss ratio was thus determined from the following equation (Escorihuela et al., 2018):

$$
\text { PA loss } \%=\frac{W_{t_{0}}-W_{t_{i}}}{W_{t_{0}}} \times 100
$$

TABLE 1 | Preparation conditions of the ABPBI polymers.

\begin{tabular}{|c|c|c|c|c|c|c|c|c|}
\hline $\begin{array}{l}\text { Polymer } \\
\text { code }\end{array}$ & $\begin{array}{c}\text { DAB } \\
(\mathrm{mmol})\end{array}$ & $\begin{array}{l}\text { PPA } \\
\text { (g) }\end{array}$ & $\begin{array}{c}\text { Time } \\
\text { (h) }\end{array}$ & $\begin{array}{c}\text { Temp. } \\
\left({ }^{\circ} \mathrm{C}\right)\end{array}$ & Solubility ${ }^{a}$ & $\begin{array}{c}\left(\eta_{i}\right) \\
(\mathrm{dL} / \mathrm{g})\end{array}$ & $\begin{array}{l}\text { Average Mw } \\
\text { (KDa) }\end{array}$ & $\begin{array}{l}\text { PA doping } \\
\text { level }^{\text {b }}\end{array}$ \\
\hline ABPBI 1 & 10 & 300 & 12 & 200 & soluble & 0.47 & 20.0 & 2.7 \\
\hline ABPBI 2 & 20 & 300 & 12 & 200 & soluble & 1.08 & 49.3 & 3.6 \\
\hline ABPBI 3 & 30 & 300 & 12 & 200 & soluble & 1.82 & 86.9 & 4.7 \\
\hline ABPBI 4 & 40 & 300 & 12 & 200 & soluble & 2.32 & 113.1 & 4.9 \\
\hline ABPBI 5 & 50 & 300 & 12 & 200 & insoluble & $N D$ & $N D$ & $N D$ \\
\hline
\end{tabular}

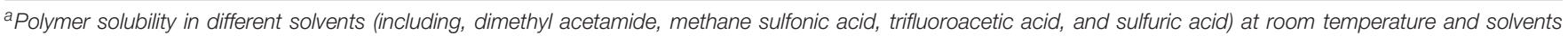

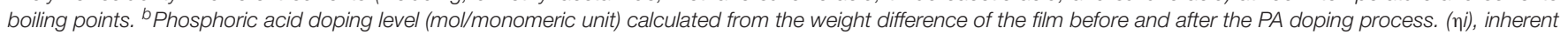
viscosity; ND, could not be determined. 
where $W t_{0}$ and $W t_{i}$ are the dry weight of the films before and after the PA retention process, respectively.

\section{Oxidative Degradation of the ABPBI Films}

The oxidative stability of the films was assessed through an oxidative radical process in a Fenton reagent. Specifically, strips of $\mathrm{ABPBI}$ films were prepared, dried at $80^{\circ} \mathrm{C}$, and immersed in a capped glass bottle containing a $50 \mathrm{ml}$ Fenton reagent of $3.0 \% \mathrm{H}_{2} \mathrm{O}_{2}$ and $4.0 \mathrm{ppm} \mathrm{Fe}^{2+}$ ions (added as ferrous nitrate). The bottles were then incubated in a preheated oven at $65^{\circ} \mathrm{C}$ for 7 days. The film samples were taken out every $24 \mathrm{~h}$, washed with deionized water, dried at $110^{\circ} \mathrm{C}$, and finally weighted to evaluate the oxidative stabilities of the films. At each measurement, the Fenton reagent was completely renewed (every 24 h) (Liao et al., 2011).

\section{IEC of ABPBI Films}

The ABPBI films were first put into a $1.0 \mathrm{M} \mathrm{HCl}$ solution. Next, they were severely washed with deionized water and then $1.0 \mathrm{M}$ $\mathrm{NaOH}$ solution for $1 \mathrm{~h}$ in each solution. Again, the films were put into the $1.0 \mathrm{M} \mathrm{HCl}$ solution for 1 day and finally rinsed in deionized water. Subsequently, the films were immersed in $50 \mathrm{ml}$ of $0.1 \mathrm{M} \mathrm{NaCl}$ solution to proceed with the ion exchange process and then were taken out, washed with deionized water, dried, and reweighed. The concentration of $\mathrm{Na}^{+}$left in the exchange media was calculated through a titration process against 0.02 $\mathrm{NaOH}$ solution. The IEC of the films was obtained using the following equation.

$$
I E C=V \times C / W
$$

where $V$ is the volume of $\mathrm{NaOH}$ consumed (L), $C$ is the concentration of $\mathrm{NaOH}(\mathrm{M})$, and $W$ is the weight of the dried film (g).

\section{Proton Conductivity}

Prior to proton conductivity testing, ABPBI films were dried at $120^{\circ} \mathrm{C}$. The proton conductivities $\left(\sigma_{i}\right)$ of the films were measured in an anhydrous environment at different temperatures using a four-probe conductivity cell that uses two separated pairs of current collectors and two voltage-sensing electrodes in order to get more accurate measurements by eliminating the contact resistance. The measurements were recorded in the frequency range $100 \mathrm{kHz}$ to $0.1 \mathrm{~Hz}$ using a frequency response analyzer (Solartron). The high-frequency intercept of the impedance spectra was used to calculate the proton conductivity $(\sigma)$ using the following equation: $\sigma=L /(R \times A)$, where $R$ is the measured resistance (high-frequency intercept of the impedance spectra),
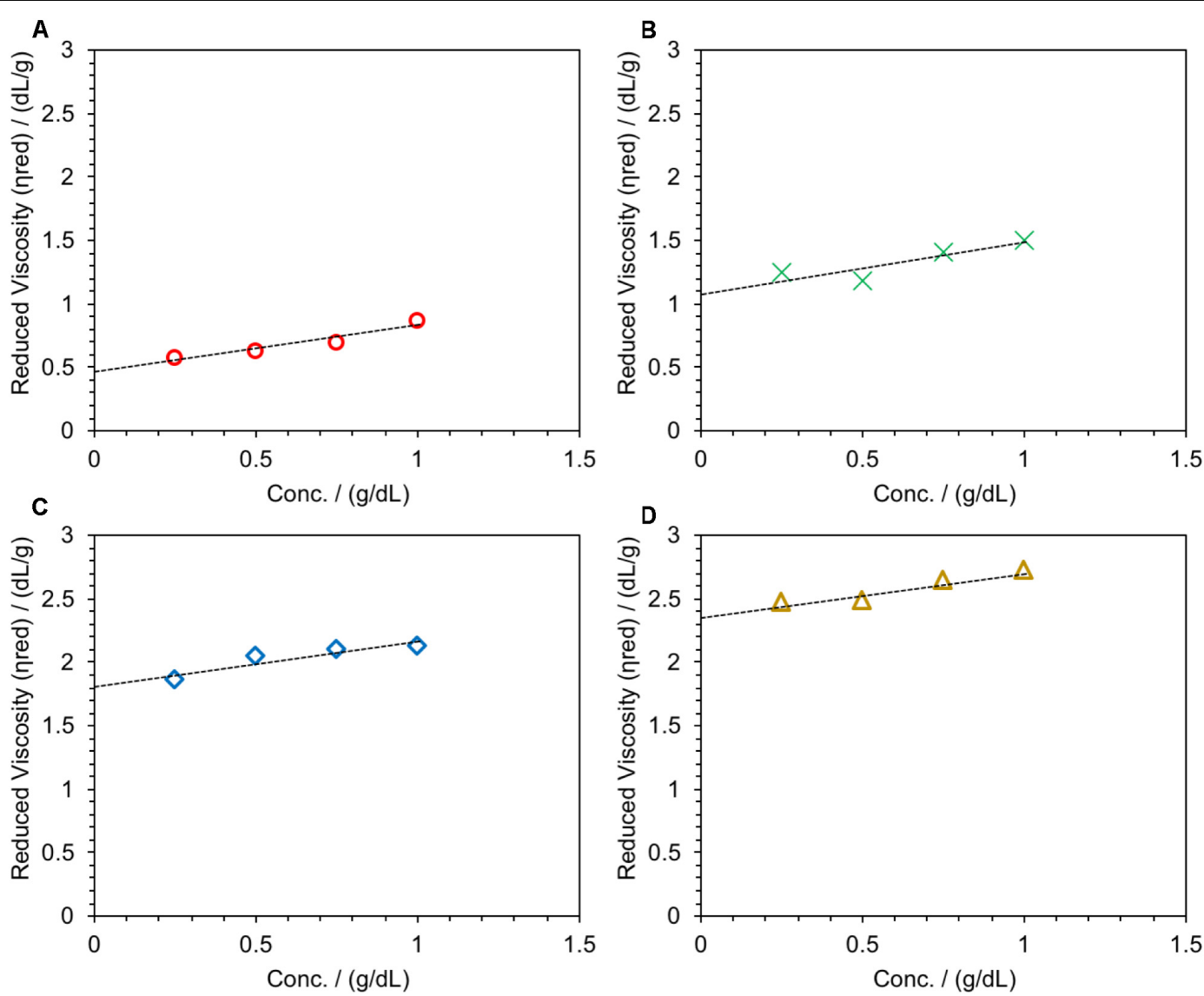

FIGURE 2 | Reduced viscosity as a function of polymer concentration in concentrated sulfuric acid at $30^{\circ} \mathrm{C}$. (A) ABPBI-1, (B) ABPBI-2, (C) ABPBI-3, and (D) ABPBI-4. 


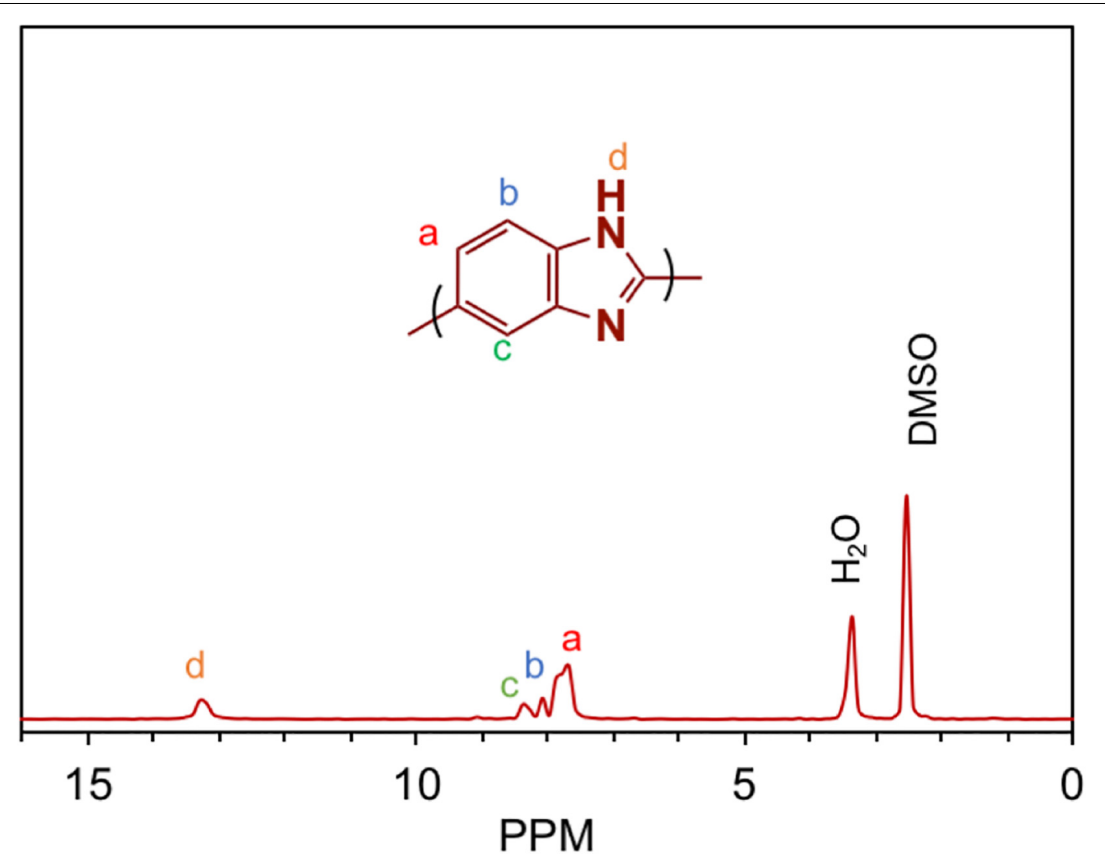

FIGURE $3 \mid{ }^{1} \mathrm{H}-\mathrm{NMR}$ spectrum of high MW ABPBI polymer.

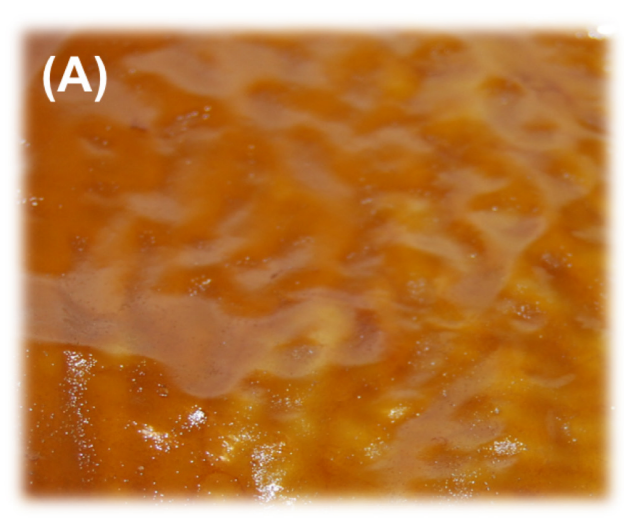

\section{(B)}
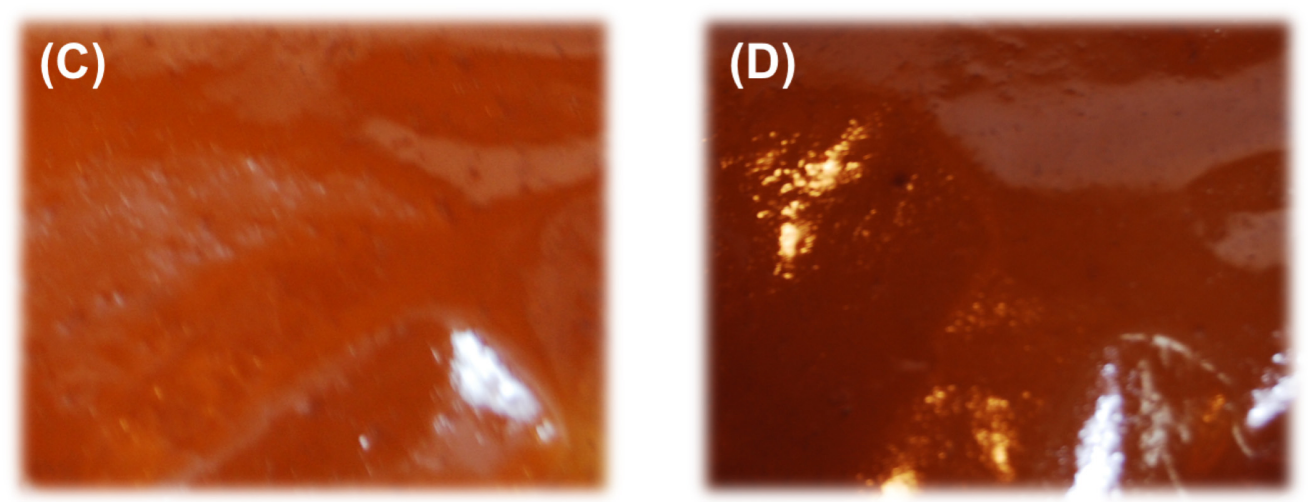

FIGURE 4 | Photo images of fabricated ABPBI films $(4 \mathrm{~cm} \times 5 \mathrm{~cm})$ : (A) ABPBI-1, (B) ABPBI-2, (C) ABPBI-3, (D) ABPBI-4. 
$L$ is the distance between the electrodes, and $A$ is the thickness of the film times the width (Müller et al., 2014).

\section{Characterization}

The NMR and FTIR spectra were measured by a Bruker $400 \mathrm{MHz}$ spectrometer (Bruker BioSpin AG) and a Perkin-Elmer Spectrum 65 FTIR, respectively. The thermal behavior (TGA) of the films was measured by a thermogravimetric analyzer (Shimadzu Corp.).

\section{RESULTS AND DISCUSSION}

Poly(2,5-benzimidazole) polymer was synthesized based on the literature reports using $\mathrm{DAB}$ as the monomer (see Figure 1; Ashino et al., 2009). The synthetic conditions were varied to get ABPBI with different MWs. Specifically, the concentration of the $\mathrm{DAB}$ monomer was changed with respect to the dehydrating agent PPA, keeping the reaction time and the condensation temperature constant at $12 \mathrm{~h}$ and $200^{\circ} \mathrm{C}$, respectively (see Table 1; Das et al., 2018). The reduced viscosities of the prepared ABPBI polymers are measured as a function of polymer concentrations as shown in Figure 2. The inherent viscosity of each ABPBI polymer was determined from the $y$-axis intercept (Caparros and Bohdanecký, 1985; Pamies et al., 2008) and used in a

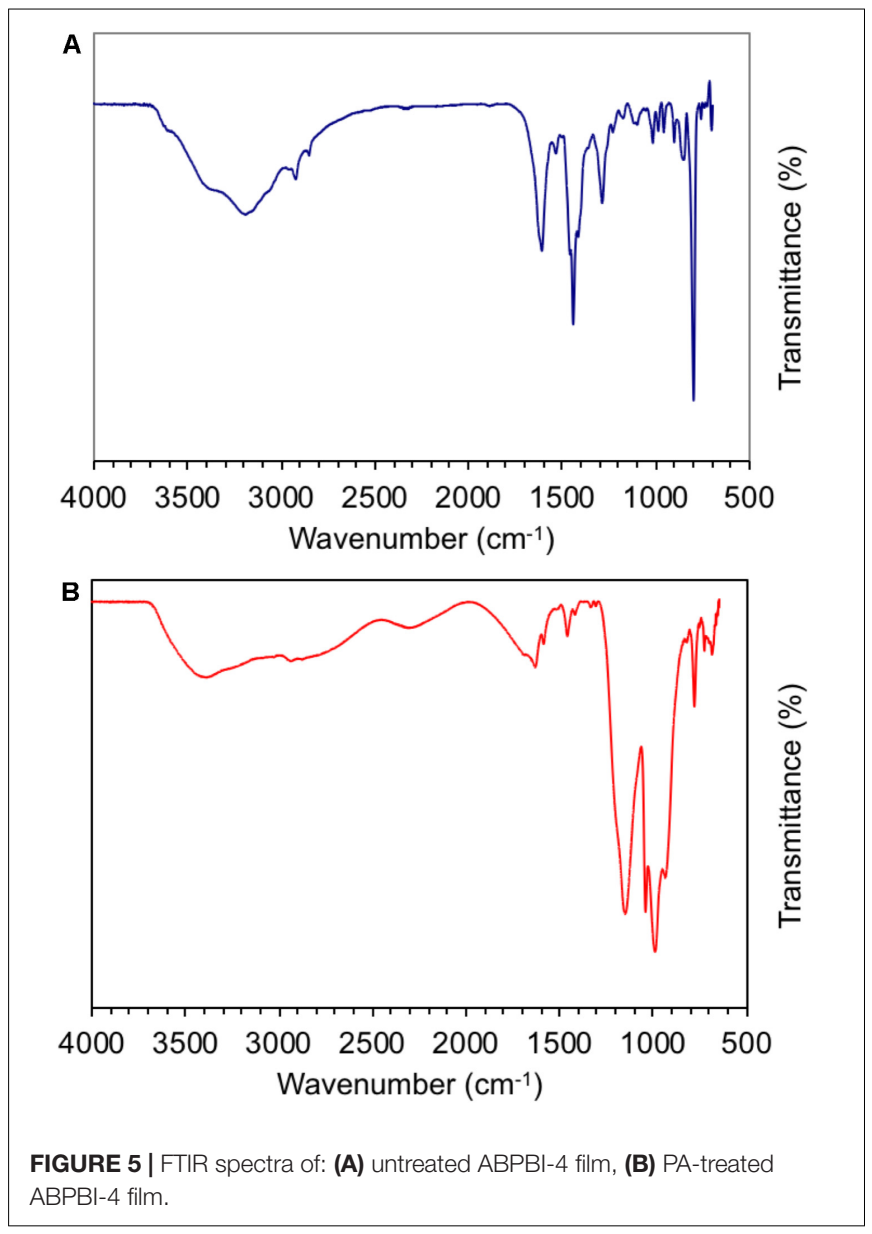

Mark-Houwink equation to obtain the polymer MW (Yuan et al., 2009). The synthesized polymers showed good dissolution behaviors in many solvents, expect for the ABPBI-5 polymer (see Table 1). The ABPBI-5 polymer showed no dissolution properties in any solvent, including dimethyl acetamide, methane sulfonic

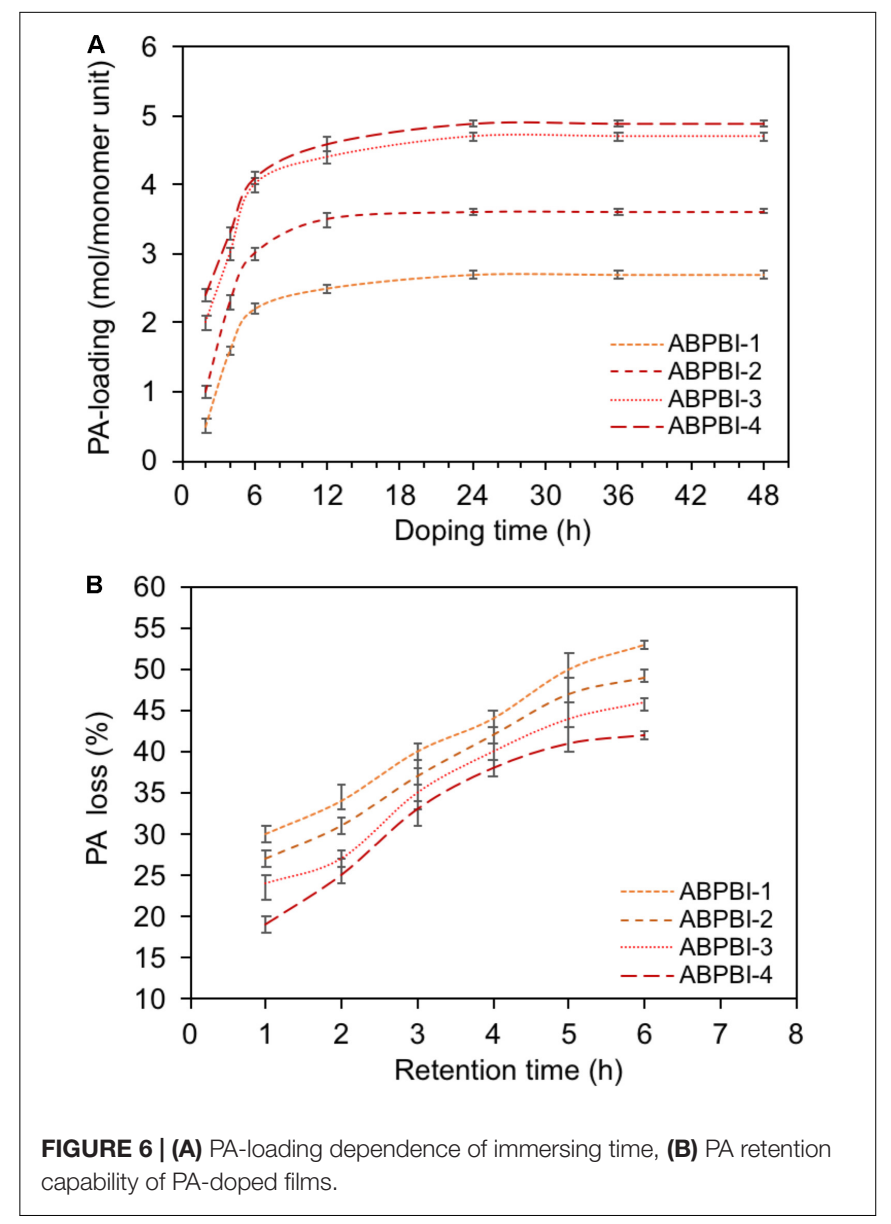

FIGURE 6 | (A) PA-loading dependence of immersing time, (B) PA retention capability of PA-doped films.

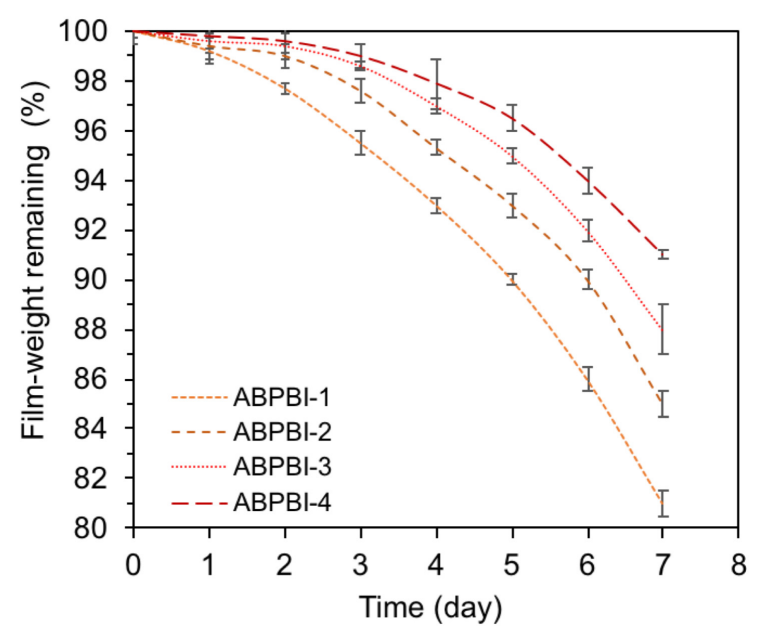

FIGURE 7 | Oxidative stability of ABPBI films in Fenton's reagent at $65^{\circ} \mathrm{C}$. 


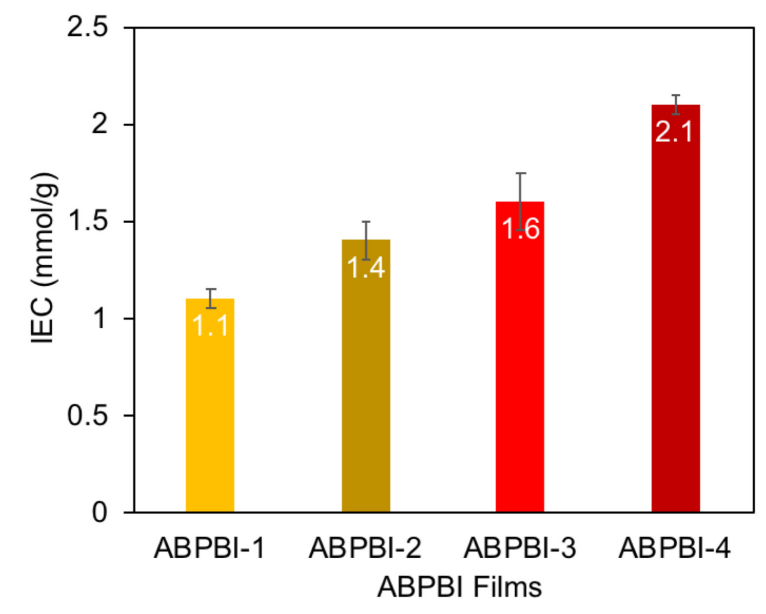

FIGURE 8 | IEC of fabricated ABPBI films.

acid, TFA, and sulfuric acid. This behavior was attributed to the synthesis of a high-MW ABPBI polymer and to the strong entanglement of the polymer chains (Choi et al., 2013).

The structure of ABPBI was confirmed on the molecular level by the NMR spectrum shown in Figure 3. As can be seen, the proton signals appearing at $\delta$ ppm 13.3 (s, N-H), 8.3 (s, Ar-H), $8.0(\mathrm{~d}, \mathrm{Ar}-\mathrm{H})$, and $7.7(1 \mathrm{H}, \mathrm{d}, \mathrm{Ar}-\mathrm{H})$ were in accordance with the literature data of ABPBI (Bhavsar et al., 2014).

Photo images of the cast films were displayed in Figure 4. As can be seen, homogenous films were successfully prepared. The films displayed different colors depending on the polymer MW. More dense brown films were obtained with the increase of polymer MW.

The FTIR spectra displayed in Figure 5 confirmed the chemical structure of ABPBI and PA-doped ABPBI films. Figure 5A shows the FTIR spectrum of the high-MW ABPBI film. The broad adsorption band at 2,600-3,650 $\mathrm{cm}^{-1}$ was assigned to the $\mathrm{NH}$ groups of the ABPBI polymer. The high density and the broadness of this band reflected a high degree of chain association and entanglement due to the strong intermolecular/intramolecular H-bonding in the film matrix. The other main characteristic bands for ABPBI recorded at 1,620, 1,535 , and $1,284 \mathrm{~cm}^{-1}$ are assigned to the stretching vibration of the $\mathrm{C}=\mathrm{N}, \mathrm{C}=\mathrm{C}$, and $\mathrm{C}-\mathrm{N}$ groups, respectively. The absorption bands observed at $2,800-3,000 \mathrm{~cm}^{-1}$ are assigned to the stretching vibration modes of the $\mathrm{C}-\mathrm{H}$ groups (Luo et al., 2012). Figure 5B shows the FTIR spectrum of the ABPBI film after the PA doping process. As can be seen, the region of the $\mathrm{NH}$ group of the pristine ABPBI film broadened further, indicating the protonation of the $\mathrm{NH}$ group. This result confirmed the formation of a strong hydrogen bonding network in the ABPBI film in which the protons can jump from the ABPBI polymer

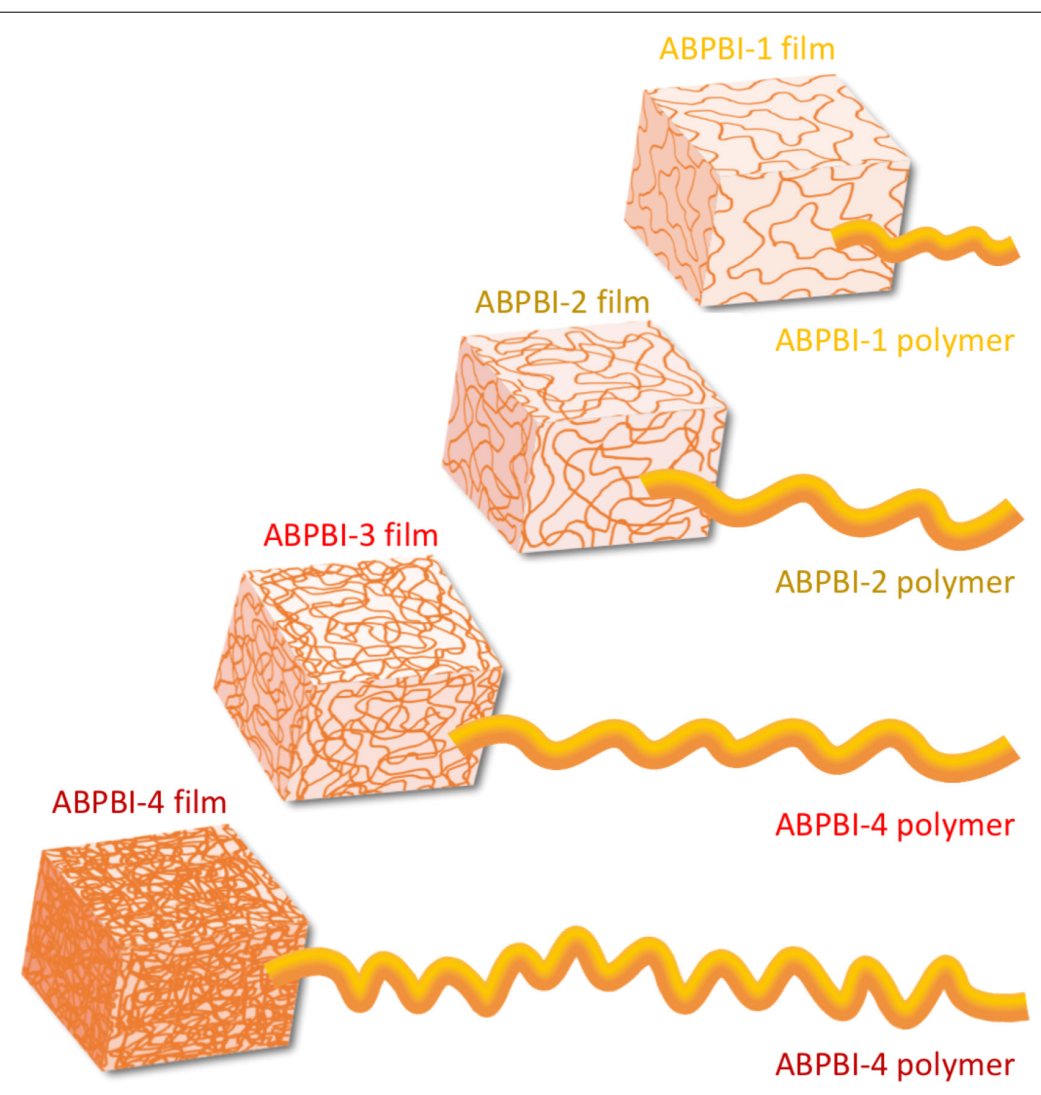

FIGURE 9 | Schematic illustration of film packing of ABPBI polymers in their corresponding films. 


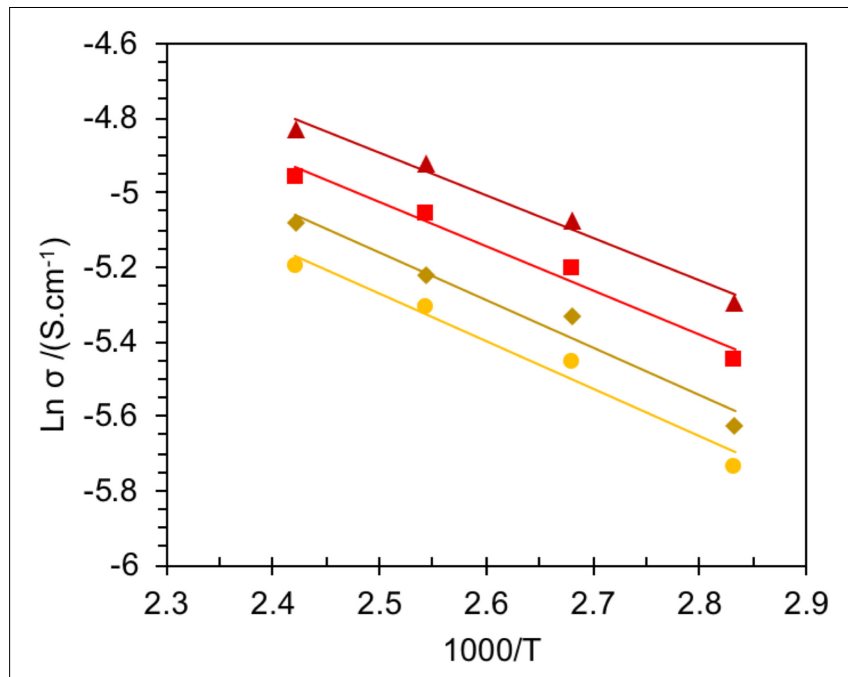

FIGURE 10 | Arrhenius plots of ABPBI films at anhydrous conditions. ABPBI-1 (yellow), ABPBI-2 (faint brown), ABPBI-3 (red), and ABPBI-4 (dark brown).

TABLE 2 | PA retention, IEC, proton conductivity, and activation energy of ABPBI films.

\begin{tabular}{|c|c|c|c|c|}
\hline Polymer code & $\begin{array}{l}\text { PA retention } \\
\text { capability (\%) }\end{array}$ & $\begin{array}{c}\mathrm{IEC} \\
(\mathrm{mmol} / \mathrm{g})\end{array}$ & $\begin{array}{c}\sigma \\
(\mathrm{mS} / \mathrm{cm})\end{array}$ & $\begin{array}{c}\mathrm{Ea} \\
(\mathrm{kJ} / \mathrm{mol})\end{array}$ \\
\hline ABPBI 1 & 47 & 1.1 & 5.5 & 10.6 \\
\hline ABPBI 2 & 51 & 1.4 & 6.2 & 10.5 \\
\hline ABPBI 3 & 54 & 1.6 & 7 & 9.7 \\
\hline ABPBI 4 & 58 & 2.1 & 8 & 9.3 \\
\hline
\end{tabular}

backbone to the PA network. The absorption bands observed at 1,046 and $985 \mathrm{~cm}^{-1}$ are assigned to the stretching modes of the phosphate ions of the loaded PA moieties. The absorption band observed at $1,240 \mathrm{~cm}^{-1}$ is assigned to the $\mathrm{P}=\mathrm{O}$ group of the phosphoric acid moieties. The other PA bands superimposed with the ABPBI bands (Nezakati et al., 2018).

Regarding the PA doping level, Figure 6A shows the PA loading dependence of the immersion time. Almost all the films achieved acid adsorption equilibrium after $24 \mathrm{~h}$ in $85 \% \mathrm{PA}$ at room temperature. The loading level of $\mathrm{PA}$ increased by the increase of ABPBI MW (see Table 1). To be specific, ABPBI-4 showed a PA loading of $4.9 \mathrm{~mol}$ per monomeric unit after $24 \mathrm{~h}$, which was higher than that of ABPBI-1 (2.7 mol per monomeric unit). Almost a twofold increase in PA loading was obtained when the MW changed from 20.0 to $113.1 \mathrm{kDa}$. Interestingly, the very high MW of ABPBI did not show any significant influence on the film loading ratio of PA. Typically, the loading level of PA slightly increased for the ABPBI-4 film which possesses an MW of $113.1 \mathrm{kDa}$. This inconsiderable increase of the PA loading ratio is attributed to the high-density packing and the strong entanglement of the ABPBI-4 chains (Lv et al., 2015). Thus, it was worth to note that the MW control of ABPBI is a very effective tool to provide useful information on the PA loading ratio.

The PA retention capability of PA-doped films is considered as one of the major issues in conductivity loss and film degradation.
Thus, a PA leaching experiment of ABPBI films is conducted to see the impact of polymer MW on the film retention capability of PA moieties. Figure 6B shows the PA retention capability as a function of retention time. After $6 \mathrm{~h}$ of experiment, the ABPBI4 retained $58 \%$ of loaded PA compared to $47 \%$ for ABPBI- 1 . The lower degree of PA leaching in the case of the ABPBI-4 film was due to the high polymer MW and the chain entanglement which incorporated and trapped more PA molecules ( $\mathrm{Lv}$ et al., 2015), preventing them from leaching out from the film. These results clearly indicated how important the ABPBI MW is to keep possession of PA moieties.

In real FC testing, hydrogen peroxide is usually produced by the incomplete reduction of the oxidant used in the reaction of electricity production. The higher the ratio of the produced hydrogen peroxide, the higher the degradation process. Typically, hydrogen peroxides dissociate into hydroxyl free radicals. These radicals attack the polymer backbone, leading to a fast degradation process of the conductive films (Zaton et al., 2017). Accordingly, the oxidative stability of the FC films is very important to be assessed. The Fenton experiment was applied to evaluate the oxidative stability of the synthesized films. Figure 7 shows the chemical oxidative stability of ABPBI films in the Fenton reagent. As can be seen, a weight loss of $9 \mathrm{wt} \%$ was observed for the ABPBI-4 film compared to $19 \mathrm{wt} \%$ for the ABPBI-1 film at the end of the experiment (after 7 days). These results indicated a lower degradation rate of $\mathrm{ABPBI}$ films when the polymer MW increased. The high stability of the ABPBI-4 film to free radical oxidative attack is attributed to the strong intermolecular and intramolecular interactions of the PA-doped polymer chains (He et al., 2006; Kerres et al., 2006).

In order to collect information about the charge density of the synthesized films, IEC was measured (He et al., 2015). Figure 8 shows the IEC as a function of ABPBI MW. As can be seen, the films exhibited higher IEC values with the increase of ABPBI MW. The ABPBI-1 showed an IEC value of $1.1 \mathrm{mmol} / \mathrm{g}$, while the ABPBI-4 showed an IEC value of $2.1 \mathrm{mmol} / \mathrm{g}$ (an increase of almost one order of magnitude in IEC). This improvement of IEC was associated with the increase of the acid doping level and the improvement of the intramolecular hydrogen bonding network resulting from the entangled polymer chains, facilitating the ion transfer process. In this regard, More et al. (2014) used molecular dynamics simulations to show the effect of polymer chain length on film properties. The results of this study emphasized that the increase of the polymer chain length led to a more dense packing of the polymer film that was a result of the improved intramolecular hydrogen bonding network. Such interaction also increased with the increase of PA doping level. Figure 9 schematically illustrated the impact of ABPBI MW on film packing, which was responsible for the improvement of the $\mathrm{PA}$ retention capability and the IEC.

To verify the above results, proton conductivity measurements were conducted. Figure $\mathbf{1 0}$ shows the proton conductivity of ABPBI films as a function of FC operating temperatures at anhydrous conditions. As a general overview, the proton conductivity of the ABPBI films increased with the increase of operating temperature, due to the improvement of the proton mobility at elevated temperatures (Melchior et al., 2017). 
TABLE 3 | Comparison of the properties of the current ABPBI membrane to the commercial membranes.

\begin{tabular}{|c|c|c|c|c|c|}
\hline $\begin{array}{l}\text { Polymer } \\
\text { code }\end{array}$ & $\begin{array}{l}\text { PA doping } \\
\text { level }\end{array}$ & $\begin{array}{l}\text { PA retention } \\
\text { capability (\%) }\end{array}$ & $\begin{array}{c}\text { IEC } \\
(\mathrm{mmol} / \mathrm{g})\end{array}$ & $\begin{array}{l}\sigma \\
(\mathrm{mS} / \mathrm{cm})\end{array}$ & References \\
\hline ABPBI & 4.9 & 58 & 2.1 & $\begin{array}{l}8.0 \text { at } 140^{\circ} \mathrm{C} \\
\text { anhydrous conditions }\end{array}$ & This work \\
\hline $\begin{array}{l}\text { Commercial } \\
\text { PBI }\end{array}$ & 5.5 & 50 & 2.57 & $\begin{array}{l}7.5 \text { at } 140^{\circ} \mathrm{C} \\
\text { anhydrous conditions }\end{array}$ & Jouanneau et al., 2006; Gao et al., 2020b \\
\hline $\begin{array}{l}\text { Commercial } \\
\text { PBI }\end{array}$ & 4.5 & 75 & $N D$ & $\begin{array}{l}7.0 \text { at } 140^{\circ} \mathrm{C} \\
\text { anhydrous conditions }\end{array}$ & Berber and Nakashima, 2019b \\
\hline $\begin{array}{l}\text { Commercial } \\
\text { PBI }\end{array}$ & 5.6 & $N D$ & $N D$ & $\begin{array}{l}26 \text { at } 140^{\circ} \mathrm{C} \\
20 \% \mathrm{RH}\end{array}$ & He et al., 2003 \\
\hline Nafion 115 & $N A$ & $N A$ & 0.9 & $\begin{array}{l}0.3 \text { at } 140^{\circ} \mathrm{C} \\
\text { anhydrous conditions }\end{array}$ & Li et al., 2010 \\
\hline Nafion 117 & $N A$ & $N A$ & 0.94 & $\begin{array}{l}9.0 \text { at } 140^{\circ} \mathrm{C} \\
90 \% \mathrm{RH}\end{array}$ & Casciola et al., 2009; Kim and Yoo, 2019 \\
\hline SPEEK & $N A$ & $N A$ & 1.42 & $\begin{array}{l}0.1 \text { at } 140^{\circ} \mathrm{C} \\
\text { anhydrous conditions }\end{array}$ & Li et al., 2010 \\
\hline
\end{tabular}

ND, not determined; NA, not applicable; sPEEK, sulfonated poly(ether ether ketone).

A maximum proton conductivity of $5.5 \mathrm{mS} / \mathrm{cm}$ was observed for the ABPBI- 1 film at $140^{\circ} \mathrm{C}$, while ABPBI-4 showed a proton conductivity of $8.0 \mathrm{mS} / \mathrm{cm}$ at the same operating temperature, achieving a $45 \%$ increase in proton conduction, thanks to the high MW of ABPBI-4 which provided good pathways for smooth proton conduction (Zhang et al., 2015; Dorenbos, 2017).

To explore the mechanism of proton conduction, the activation energies (Ea) were evaluated by fitting the Arrhenius plots shown in Figure 10. The obtained Ea values are collected and summarized in Table 2. As noticed, Ea decreased with the increase of both polymer $\mathrm{MW}$ and PA loading ratio. The Ea values for ABPBI-1 and ABPBI-4 films were 10.6 and $9.3 \mathrm{~kJ} / \mathrm{mol}$, respectively. These low Ea values account for the Grotthuss mechanism (proton jumping) with a high proton conductivity.

In order to highlight the properties of the current ABPBI membranes, a comparison to the well-known and commercial membranes was conducted. As noticed, the ABPBI membrane with the highest MW has shown remarkable properties in comparison to the commercial PBI Nafion and sPEEK. Specifically, the proton conductivity and the PA retention capability were higher than those of the commercial PBI, thanks to the control of the MW of the ABPBI polymer. The proton conductivity and the IEC were also higher than those of Nafion and sPEEK at the same measurement conditions (see details of Table 3). These improved results are on the way to reaching the worldwide targets of high-temperature PEFC (Sun et al., 2019).

\section{CONCLUSION}

A series of ABPBI polymers with different MWs ranging from 20 to $113 \mathrm{KDa}$ were synthesized and fabricated into conductive films to show the impact of ABPBI MW on film physicochemical properties. Notably, the PA loading ratio reached $4.9 \mathrm{~mol}$ per monomeric unit of ABPBI at an MW of $113 \mathrm{kDa}$. The acid PA retention capability improved with the increase of ABPBI MW, thanks to the chain entanglement which incorporated and trapped more PA molecules. The fabricated ABPBI films exhibited good oxidative stability. A weight loss of only $9 \mathrm{wt} \%$ was observed for the ABPBI-4 film compared to $19 \mathrm{wt} \%$ for the ABPBI- 1 film after 7 days in the Fenton reagent at $65^{\circ} \mathrm{C}$. The IEC value increased by an order of magnitude when the ABPBI MW changed from 20 to $133 \mathrm{kDa}$. A maximum proton conductivity of $8.0 \mathrm{mS} / \mathrm{cm}$ was recorded for the ABPBI- 4 film at $140^{\circ} \mathrm{C}$, which was $45 \%$ higher than that for the ABPBI-1 film. The proton conduction process followed the Grotthuss mechanism with a low activation energy $(9.3 \mathrm{~kJ} / \mathrm{mol})$ at high ABPBI MW. These results indicated how important the polymer $\mathrm{MW}$ is in obtaining conductive films with remarkable properties for FC applications.

\section{DATA AVAILABILITY STATEMENT}

The original contributions presented in the study are included in the article/supplementary material, further inquiries can be directed to the corresponding author.

\section{AUTHOR CONTRIBUTIONS}

The author confirms being the sole contributor of this work and has approved it for publication.

\section{FUNDING}

The Deanship of Scientific Research at Jouf University funded this research through the Fast-track Research Funding Program, the author is grateful for the support. 


\section{REFERENCES}

Asensio, J. A., Sánchez, E. M., and Gómez-Romero, P. (2010). Proton-conducting membranes based on benzimidazole polymers for high-temperature PEM fuel cells. a chemical quest. Chem. Soc. Rev. 39, 3210-3239. doi: 10.1039/b922650h

Ashino, N., Martins Camargo, A. P., Morgado, D. L., Frollini, E., and Gonzalez, E. (2009). Development of electrolyte membranes for fuel cells operating at intermediate temperatures $\left(130-200^{\circ}\right)$. ECS Transact. 19, 51-62. doi: 10.1149/ 1.3253362

Bao, X., Zhang, F., and Liu, Q. (2015). Sulfonated poly(2,5-benzimidazole) (ABPBI)/ MMT/ ionic liquids composite membranes for high temperature PEM applications. Int. J. Hydrogen Energy 40, 16767-16774. doi: 10.1016/j. ijhydene.2015.07.127

Berber, M. R., Fujigaya, T., and Nakashima, N. (2018). A potential polymer formulation of a durable carbon-black catalyst with a significant fuel cell performance over a wide operating temperature range. Mater. Today Energy 10, 161-168. doi: 10.1016/j.mtener.2018.08.016

Berber, M. R., and Nakashima, N. (2019a). Bipyridine-based polybenzimidazole membranes with outstanding hydrogen fuel cell performance at high temperature and non-humidifying conditions. J. Membrane Sci. 591:117354. doi: 10.1016/j.memsci.2019.117354

Berber, M. R., and Nakashima, N. (2019b). Tailoring different molecular weight phenylene-polybenzimidazole membranes with remarkable oxidative stability and conductive properties for high-temperature polymer electrolyte fuel cells. ACS Appl. Mater. Interfaces 11, 46269-46277. doi: 10.1021/acsami.9b18314

Bhavsar, R. S., Kumbharkar, S. C., Rewar, A. S., and Kharul, U. K. (2014). Polybenzimidazole based film forming polymeric ionic liquids: synthesis and effects of cation-anion variation on their physical properties. Poly. Chem. 5, 4083-4096. doi: 10.1039/c3py01709e

Caparros, A. M. R., and Bohdanecký, M. (1985). A note on the intrinsic viscosity and huggins coefficient of low-molecular-weight polymers in mixed solvents. Die Makromolekulare Chemie 186, 1005-1013.

Casciola, M., Capitani, D., Donnadio, A., Frittella, V., Pica, M., and Sganappa, M. (2009). Preparation, proton conductivity and mechanical properties of nafion 117-zirconium phosphate sulphophenylphosphonate composite membranes. Fuel Cells 9, 381-386. doi: 10.1002/fuce.200800128

Choi, S.-W., Park, J. O., Pak, C., Choi, K. H., Lee, J.-C., and Chang, H. (2013). Design and synthesis of cross-linked copolymer membranes based on poly(benzoxazine) and polybenzimidazole and their application to an electrolyte membrane for a high-temperature PEM fuel cell. Polymers 5, 77-111. doi: 10.3390/polym5010077

Das, A., Ghosh, P., Ganguly, S., Banerjee, D., and Kargupta, K. (2018). Salt-leaching technique for the synthesis of porous poly(2,5-benzimidazole) (ABPBI) membranes for fuel cell application. J. Appl. Poly. Sci. 135:45773. doi: 10.1002/ app. 45773

Das, T. K., and Prusty, S. (2012). Review on conducting polymers and their applications. Poly-Plast. Technol. Eng. 51, 1487-1500.

Dorenbos, G. (2017). Improving proton conduction pathways in di- and triblock copolymer membranes: branched versus linear side chains. J. Chem. Phys. 146:244909. doi: 10.1063/1.4989487

Escorihuela, J., Sahuquillo, Ó, García-Bernabé, A., Giménez, E., and Compañ, V. (2018). Phosphoric Acid Doped Polybenzimidazole (PBI)/Zeolitic imidazolate framework composite membranes with significantly enhanced proton conductivity under low humidity conditions. Nanomaterials (Basel, Switzerland) 8:775. doi: 10.3390/nano8100775

Fujigaya, T., Berber, M. R., and Nakashima, N. (2014). Design of highly durable electrocatalyst for high-temperature polymer electrolyte fuel cell. ECS Transact. 64, 159-169. doi: 10.1149/06403.0159ecst

Fujigaya, T., Hirata, S., Berber, M. R., and Nakashima, N. (2016). Improved durability of electrocatalyst based on coating of carbon black with polybenzimidazole and their application in polymer electrolyte fuel cells. ACS Appl. Mater. Interfaces 8, 14494-14502. doi: 10.1021/acsami.6b01316

Gao, C., Hu, M., Wang, L., and Wang, L. (2020a). Synthesis and properties of phosphoric-acid-doped polybenzimidazole with hyperbranched cross-linkers decorated with imidazolium groups as high-temperature proton exchange membranes. Polymers 12:515. doi: 10.3390/polym 12030515

Gao, F., Li, X., Zhang, X., Liu, W., and Liu, C. (2020b). Enhancement on both phosphoric acid retention and proton conduction of polybenzimidazole membranes by plasma treatment. Colloids Surfaces Physicochem. Eng. Aspects 603:125197. doi: 10.1016/j.colsurfa.2020.125197

Hafez, I. H., Berber, M. R., Fujigaya, T., and Nakashima, N. (2017). High electronic conductivity and air stability of ultrasmall copper-metal nanoparticles supported on pyridine-based polybenzimidazole carbon nanotube composite. ChemCatChem 9, 4282-4286. doi: 10.1002/cctc.201700921

He, R., Li, Q., Bach, A., Jensen, J. O., and Bjerrum, N. J. (2006). Physicochemical properties of phosphoric acid doped polybenzimidazole membranes for fuel cells. J. Membrane Sci. 277, 38-45. doi: 10.1016/j.memsci.2005. 10.005

He, R., Li, Q., Xiao, G., and Bjerrum, N. J. (2003). Proton conductivity of phosphoric acid doped polybenzimidazole and its composites with inorganic proton conductors. J. Membrane Sci. 226, 169-184. doi: 10.1016/j.memsci.2003. 09.002

He, Y., Zhang, H., Li, Y., Wang, J., Ma, L., Zhang, W., et al. (2015). Synergistic proton transfer through nanofibrous composite membranes by suitably combining proton carriers from the nanofiber mat and pore-filling matrix. J. Mater. Chem. A 3, 21832-21841. doi: 10.1039/c5ta03601a

Hu, M., Pearce, E. M., and Kwei, T. K. (1993). Modification of polybenzimidazole: synthesis and thermal stability of poly(N1-methylbenzimidazole) and poly(N1,N3-dimethylbenzimidazolium) salt. J. Poly. Sci. Part A: Poly. Chem. 31, 553-561. doi: 10.1002/pola.1993.080310228

Jouanneau, J., Mercier, R., Gonon, L., and Gèbel, G. (2006). Novel proton conducting polybenzimidazole (PBI) membranes. Macromolecules 40, 983-990. doi: $10.1021 / \mathrm{ma0614139}$

Kerres, J. A., Xing, D., and Schönberger, F. (2006). Comparative investigation of novel PBI blend ionomer membranes from nonfluorinated and partially fluorinated poly arylene ethers. J. Poly. Sci. Part B: Poly. Phys. 44, 2311-2326. doi: 10.1002/polb.20862

Kim, A. R., and Yoo, D. J. (2019). A Comparative study on physiochemical, thermomechanical, and electrochemical properties of sulfonated poly(Ether Ether Ketone) block copolymer membranes with and without $\mathrm{Fe} 3 \mathrm{O} 4$ nanoparticles. Polymers 11:536. doi: 10.3390/polym11030536

Kimura, T., Matsumoto, A., Inukai, J., and Miyatake, K. (2020). Highly anion conductive polymers: how do hexafluoroisopropylidene groups affect membrane properties and alkaline fuel cell performance? ACS Appl. Energy Mater. 3, 469-477. doi: 10.1021/acsaem.9b01733

Kumar, B. S., Sana, B., Unnikrishnan, G., Jana, T., and Kumar, K. S. S. (2020). Polybenzimidazole co-polymers: their synthesis, morphology and high temperature fuel cell membrane properties. Poly. Chem. 11, 1043-1054. doi: 10.1039/c9py01403a

Li, W., Manthiram, A., and Guiver, M. D. (2010). Acid-base blend membranes consisting of sulfonated poly(ether ether ketone) and 5-amino-benzotriazole tethered polysulfone for DMFC. J. Membrane Sci. 362, 289-297. doi: 10.1016/j. memsci.2010.06.059

Liao, J. H., Li, Q. F., Rudbeck, H. C., Jensen, J. O., Chromik, A., Bjerrum, N. J., et al. (2011). Oxidative degradation of polybenzimidazole membranes as electrolytes for high temperature proton exchange membrane fuel cells. Fuel Cells 11, 745-755. doi: 10.1002/fuce.201000146

Liu, Q., Ni, N., Sun, Q., Wu, X., Bao, X., Fan, Z., et al. (2018). Poly(2,5benzimidazole)/trisilanolphenyl POSS composite membranes for intermediate temperature PEM fuel cells. J. Wuhan University Technol.-Mater. Sci. Ed. 33, 212-220. doi: 10.1007/s11595-018-1808-x

Luo, H., Vaivars, G., Agboola, B., Mu, S., and Mathe, M. (2012). Anion exchange membrane based on alkali doped poly(2,5-benzimidazole) for fuel cell. Solid State Ionics 208, 52-55. doi: 10.1016/j.ssi.2011.11.029

Lv, Y., Lin, Y., Chen, F., Li, F., Shangguan, Y., and Zheng, Q. (2015). Chain entanglement and molecular dynamics of solution-cast PMMA/SMA blend films affected by hydrogen bonding between casting solvents and polymer chains. RSC Adv. 5, 44800-44811. doi: 10.1039/c5ra06663h

Melchior, J.-P., Majer, G., and Kreuer, K.-D. (2017). Why do proton conducting polybenzimidazole phosphoric acid membranes perform well in hightemperature PEM fuel cells? Phys. Chem. Chem. Phys. 19, 601-612. doi: 10. 1039/c6cp05331a

More, M., Sunda, A. P., and Venkatnathan, A. (2014). Polymer chain length, phosphoric acid doping and temperature dependence on structure and dynamics of an ABPBI [poly(2,5-benzimidazole)] polymer electrolyte membrane. RSC Adv. 4, 19746-19755. doi: 10.1039/c4ra01421a 
Müller, F., Ferreira, C. A., Azambuja, D. S., Alemán, C., and Armelin, E. (2014). Measuring the proton conductivity of ion-exchange membranes using electrochemical impedance spectroscopy and through-plane cell. J. Phys. Chem. B 118, 1102-1112. doi: 10.1021/jp409675z

Nayak, R., Sundarraman, M., Ghosh, P. C., and Bhattacharyya, A. R. (2018). Doped poly (2,5-benzimidazole) membranes for high temperature polymer electrolyte fuel cell: influence of various solvents during membrane casting on the fuel cell performance. Eur. Poly. J. 100, 111-120. doi: 10.1016/j.eurpolymj.2017. 08.026

Nezakati, T., Seifalian, A., Tan, A., and Seifalian, A. M. (2018). Conductive polymers: opportunities and challenges in biomedical applications. Chem. Rev. 118, 6766-6843. doi: 10.1021/acs.chemrev.6b00275

Pamies, R., Hernández Cifre, J. G., Del Carmen López Martínez, M., and García De La Torre, J. (2008). Determination of intrinsic viscosities of macromolecules and nanoparticles. Comparison of single-point and dilution procedures. Colloid Poly. Sci. 286, 1223-1231. doi: 10.1007/s00396-008-1902-2

Patra, B. C., Khilari, S., Satyanarayana, L., Pradhan, D., and Bhaumik, A. (2016). A new benzimidazole based covalent organic polymer having high energy storage capacity. Chem. Commun. 52, 7592-7595. doi: 10.1039/c6cc02011a

Rath, R., Kumar, P., Unnikrishnan, L., Mohanty, S., and Nayak, S. K. (2020). Current Scenario of Poly (2,5-Benzimidazole) (ABPBI) as Prospective PEM for Application in HT-PEMFC. Poly. Rev. 60, 267-317. doi: 10.1080/15583724. 2019.1663211

Sun, X., Simonsen, S. C., Norby, T., and Chatzitakis, A. (2019). Composite membranes for high temperature PEM fuel cells and electrolysers: a critical review. Membranes 9:83. doi: 10.3390/membranes 9070083

Yang, J., and He, R. (2010). Preparation and characterization of polybenzimidazole membranes prepared by gelation in phosphoric acid. Poly. Adv. Technol. 21, 874-880. doi: 10.1002/pat.1513
Yang, Z., Berber, M. R., and Nakashima, N. (2015). Design of polymer-coated multi-walled carbon Nanotube/Carbon black-based fuel cell catalysts with high durability and performance under non-humidified condition. Electrochimica Acta 170, 1-8. doi: $10.1016 /$ j.electacta.2015.04.122

Yuan, Y., Johnson, F., and Cabasso, I. (2009). Polybenzimidazole (PBI) molecular weight and Mark-Houwink equation. J. Appl. Poly. Sci. 112, 3436-3441. doi: 10.1002/app.29817

Zatoñ, M., Rozière, J., and Jones, D. J. (2017). Current understanding of chemical degradation mechanisms of perfluorosulfonic acid membranes and their mitigation strategies: a review. Sustainable Energy Fuels 1, 409-438. doi: 10. 1039/c7se00038c

Zhan, C., Yu, G., Lu, Y., Wang, L., Wujcik, E., and Wei, S. (2017). Conductive polymer nanocomposites: a critical review of modern advanced devices. J. Mater. Chem. C 5, 1569-1585. doi: 10.1039/c6tc04269d

Zhang, H., Wu, W., Wang, J., Zhang, T., Shi, B., Liu, J., et al. (2015). Enhanced anhydrous proton conductivity of polymer electrolyte membrane enabled by facile ionic liquid-based hoping pathways. J. Membrane Sci. 476, 136-147. doi: 10.1016/j.memsci.2014.11.033

Conflict of Interest: The author declares that the research was conducted in the absence of any commercial or financial relationships that could be construed as a potential conflict of interest.

Copyright $\odot 2020$ Berber. This is an open-access article distributed under the terms of the Creative Commons Attribution License (CC BY). The use, distribution or reproduction in other forums is permitted, provided the original author(s) and the copyright owner(s) are credited and that the original publication in this journal is cited, in accordance with accepted academic practice. No use, distribution or reproduction is permitted which does not comply with these terms. 